\title{
Out of reach? \\ Convergence to an inflation target in the Central Bank of Iceland's macroeconomic model
}

\author{
Friðrik Már Baldursson and Axel Hall ${ }^{1}$
}

\begin{abstract}
Inflation scenarios in forecasts of the Central Bank of Iceland (CBI) appear to converge to the inflation target $(2.5 \%)$ in $8-9$ quarters. We ask whether this is a coincidence or an inherent property of the CBI's model, QMM. We formulate a sub-model, containing equations for inflation, inflation expectations, wages, exchange rate and the policy interest rate. We find that rapid convergence toward the inflation target is a property of the QMM when a Taylor-rule is included in the model. Underlying is an inflation expectations equation which assumes a high degree of credibility of the CBI. This equation, however, lacks empirical underpinnings. When we replace the QMM expectations equation with an estimated equation, a more realistic picture emerges where the Central Bank has to raise the policy rate considerably higher than in QMM scenarios and it takes much longer to reach the inflation target.
\end{abstract}

JEL: E27, E44, E52.

Key concepts: Inflation targeting, inflation forecasts, inflation expectations, macroeconomic models, credibility.

1 Friðrik Már Baldursson is Professor at the University of Reykjavik, School of Business. Axel Hall is Assistant Professor at the University of Reykjavik, School of Business. The authors wish to thank Guðmundur Guðmundsson, Katrín Ólafsdóttir, Pórarinn Pétursson, Porvarður Tjörvi Ólafsson and participants in a conference on Monetary Policy and Exchange Rates at 


\section{Introduction ${ }^{2}$}

Since March 2001 monetary policy in Iceland has centred on the Central Bank of Iceland (CBI) applying its policy interest rate in support of the objective of limiting inflation to about $2.5 \%$ "within an acceptable [time] horizon". ${ }^{3}$ This approach - monetary policy with an inflation target - has recently attracted controversy; although the CBI's policy interest rate has been raised from 5.16\% in February 2003 to 15.5\% in April 2008, the attempt to control inflation has not been successful, with inflation at the time we write this in June 2008 running at an annual rate of about $12 \%$.

Figure 1.1 The CBI's projected inflation timepath.

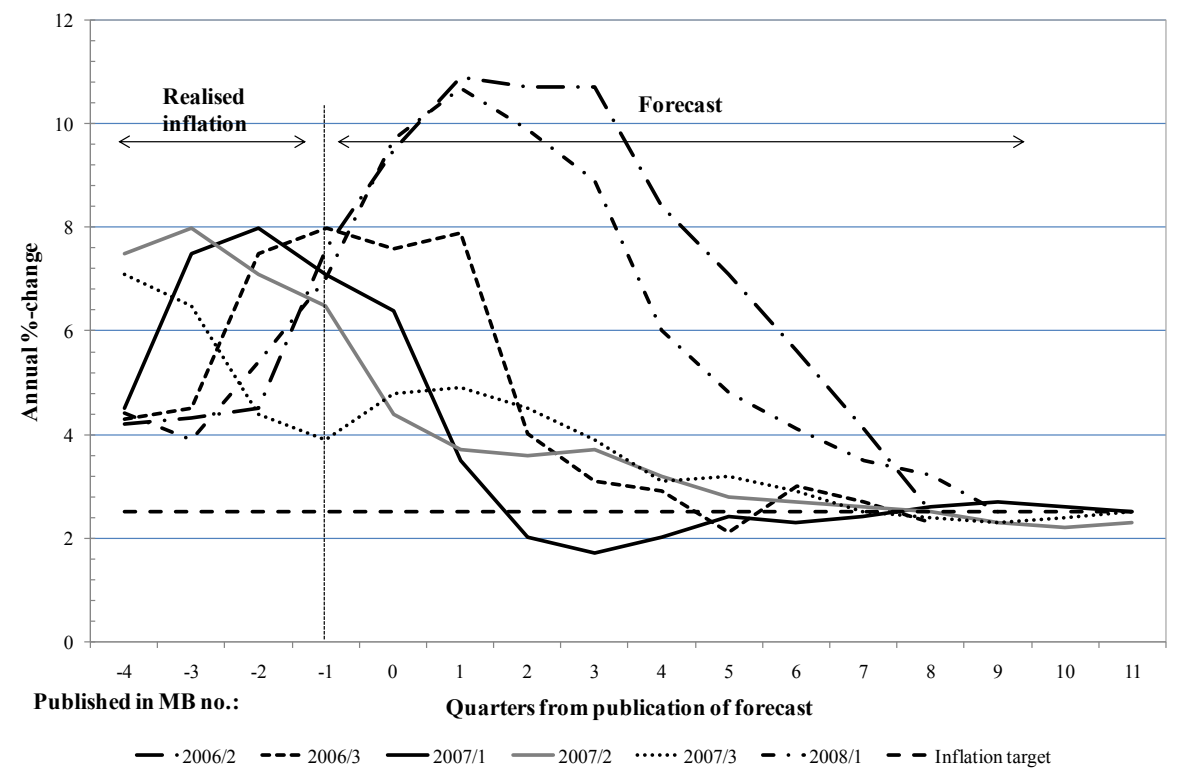

It has been suggested, among other things, that the inflation target is a kind of mirage; viz. that the CBI routinely announces that inflation certainly exceeds the target now and therefore the policy interest rate must be increased, but that inflation will then subside over the next few quarters, making it possible to lower the policy interest rate again. In fact, however, inflation has intensified and the point in time when the inflation target is to be achieved recedes like a mirage pursued by a wanderer in the desert. When the CBI's recent projections are reviewed there seems to be some validity to this contention. As shown in Figure 1.1, irrespective of the rate of inflation when a projection is made, the inflation target should be reached after 8-9 quarters (quarter when the projection is published is no. 0 on the time axis, the first quarter thereafter is no. 1 and so on). ${ }^{4}$ As

2 Professor Guðmundur Magnusson wrote extensively on monetary economics and served on the board of the Central Bank of Iceland for many years.

3 Cf. "Monetary policy and its instruments", Monetary Bulletin 2008/1, p. 113. On the economics of inflation targeting see e.g. Woodford (2007), Svensson (1997) and Svensson (1999).

4 Figures 1.1 and 1.2 are based on data from several issues of the CBI's Monetary Bulletin (Central Bank of Iceland, 2006ab, 2007abc, 2008a). 
shown in Figure 1.2 reality has been different; the projections have not materialised and the inflation rate has not been brought down. This indicates that the CBI faces a credibility problem: in the bank's view, inflation expectations are the principal determinant of inflation; in order to attain its objective the bank must persuade the market that inflation will be tamed, but that has proven a difficult task. ${ }^{5}$

Figure 1.2 Inflation and projected inflation.

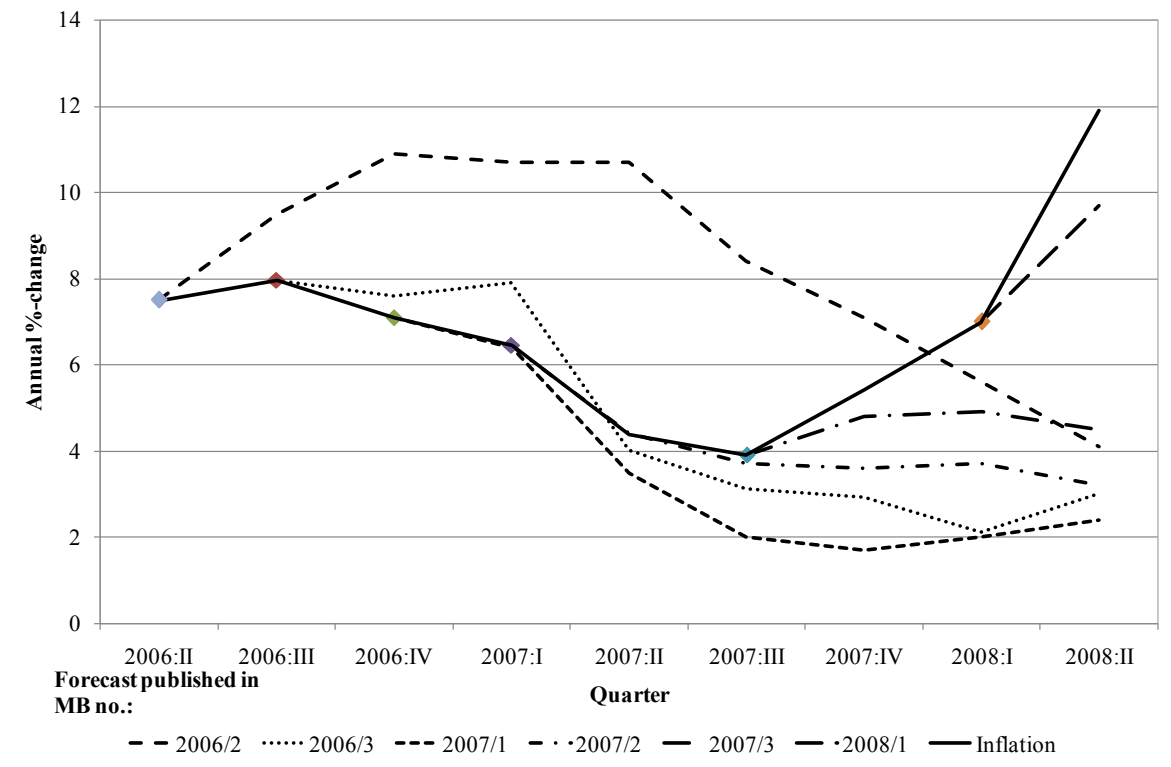

But why do the CBI's inflation projections converge towards the inflation target over a period of a little over two years? Is this coincidence or is there systematic bias in the bank's projections? To analyse this, the bank's methods of forecasting must be examined. In this respect, the CBI's quarterly macroeconomic model plays a key role. The model was adopted at the beginning of 2006 and has been used to make the CBI's unconditional inflation projections since March 2007 when the bank began to publish such projections. ${ }^{6}$ To understand how the CBI's projections unfold over time the model's dynamic characteristics must be examined. These concern the evolution of inflation and inflation expectations and other related variables when looking several quarters into the future. In this paper, therefore, attention is focused on the effects of shocks on the QMMmodel, how such shocks are reflected in inflation, interest and exchange rates and how long the system takes to regain equilibrium in their aftermath.

5 See e.g. Figure I.8 in the CBI's Economic Indicators, Central Bank of Iceland (2008b) for the development of various measures of inflation expectations.

6 Until 2007 main forecasts of the CBI were conditional upon a certain interest rate path - e.g. that interest rates would remain fixed. However, alternative forecasts based on the assumption that the CBI would respond to inflation developments according to a Taylor-rule were published in Monetary Bulletin 2006/2 and 2006/3. These alternative forecasts from 2006 are shown in Figures 1.1 and 1.2 together with the unconditional forecasts published in Monetary Bulletin beginning with 2007/1, for these would seem to be comparable forecasts. 
The model is not presented here in its entirety. Rather, an attempt is made to approach its core by defining a partial model based on several important equations of the model the "heart" of the model - which are the principal determinants of the policy interest rate's effectiveness over a relatively short period of time. These are equations which project inflation, inflation expectations, the policy interest rate, wages, and the exchange rate. The model contains no demand variables (i.e. private consumption, investment, gross domestic product etc.) which means that certain variables that are derived from these demand variables and influence inflation (output gap and unemployment) are taken as given.

Since only a part of the model is being examined, some of the equations must be simplified. A detailed account of these simplifications and their likely effects is presented below. Furthermore, the effects on the conclusions of taking the demand variables as given are discussed. In our view the influence of these deviations from the CBI model on the factors under study are minor. We consider it unlikely that the report's substantive conclusions would be different if the study were based on the model as a whole.

It should be made clear that in this paper we focus our attention on the limited aspect of the implementation of monetary policy in Iceland described above, viz. dynamic aspects of the inflation mechanism in the CBI's macroeconomic model. In particular, the paper is not a review of monetary policy or inflation targeting in Iceland.

In the next section we discuss the theoretical background of the CBI's macroeconomic model, which can in part be traced back to a corresponding model at the Bank of England used in 1999-2004. In particular, we direct our attention to the equation for inflation expectations in the CBI's model and the importance of credibility in a technical sense, viz. the weight given to the CBI's inflation target in the projection of inflation expectations. In Section 3 the econometric basis for the QMM inflation and inflation expectations equations is discussed; this section is based mostly on Guðmundur Guðmundsson (2008). In Section 4 we formulate a simplified version of the inflation part of QMM and investigate the dynamic properties of the model by introducing a shock to inflation expectation. Section 5 discusses likely effects of our simplifying assumptions. Section 6 concludes.

\section{Theoretical background}

The Central Bank of Iceland introduced its new projection model, QMM (Quarterly Macroeconomic Model), in Monetary Bulletin 2006/1 and has since used it for making projections. QMM is a quarterly model which means that a quarterly data base had to be developed in preparation for its construction. The entire model, as well as a database and a handbook (Danielsson et al., 2007) which explains the model's structure and characteristics, is published on the bank's website. Technical discussion and research into the monetary transmission mechanism are greatly facilitated by the clarity of the CBI's presentation and publication of QMM and its database. This makes a study such as the present one possible and is to the CBI's great credit. As stated in Danielsson et al. 
(2007), account was taken of the Bank of England's macroeconomic model (MM) in the model's development. It is especially clear that the determination of inflation expectations in QMM is to a considerable degree based on MM. To offer insight into the CBI's model and the economic background of its inflation section, a brief review follows of that section of the Bank of England's model.

\subsection{The economic basis of the QMM inflation model}

As stated before, the CBI's model is partly derived from the Bank of England's macroeconomic model which was used during 1999-2004 when it was replaced by a new model. ${ }^{7}$ The Bank of England's model is documented in detail on the bank's website. ${ }^{8}$ In many respects, the analysis of the Bank of England's model offers insight into the characteristics of the CBI's model. It is worth pausing to review certain aspects especially in this connection. The CBI's model embodies a direct estimate of a Phillips curve. In contrast, the Phillips curve is not explicit in the Bank of England's model, which presents prices in the form of a mark-up over long-term labour unit costs and determines nominal wages based on dynamic contracts. These wage and price equations in the Bank of England's model can be formally used to present a Phillips curve in the form.

$$
\pi_{t}=A(L) \pi_{t+1}^{e}+B(L) \pi_{t-1}+C(L)\left(U_{t}-U_{t}^{*}\right)+D(L)\left(y_{t}-y_{t}^{*}\right)+E(L) V_{t}
$$

where $\pi_{t}$ is inflation at time $t, \pi_{t+1}^{e}$ are inflation expectations at time $t+1, U_{t}$ is unemployment at time $t, U_{t}^{*}$ is the natural rate of unemployment, $y_{t}$ is logarithm of output, $y_{t}^{*}$ is potential output $(\log ), V_{t}$ is a vector of variables, e.g. import prices, $A(L)$ a forward polynomial, and $B(L), C(L), D(L)$ and $E(L)$ are lagged polynomials. Constraints on the polynomials' coefficients (sum one) $A$ and $B$ ensure a vertical Phillips curve in the long run. The Bank of England notes that forward-looking Phillips curves have been estimated there by using the so-called general-to-specific methodology. The results are based on quarterly data 1979-1997:

$$
\begin{aligned}
\pi_{t}= & 0.175 \pi_{t+4}^{e}+0.825 \pi_{t-1}+0.265 \Delta\left(y_{t-1}-y_{t-1}^{*}\right)+0.084\left(y_{t-4}-y_{t-4}^{*}\right) \\
& +0.009 \Delta_{4} \text { poil }_{t-4}-0.026 d 80 Q 3
\end{aligned}
$$

where $\pi$ is annual inflation, poil is the price of oil and $d 80 Q 3$ is a dummy variable for the third quarter of 1980. Expected inflation was estimated on the basis of surveys of inflation expectations of consumers. Phillips curves are used in parallel with the Bank of England's model for error testing and consistency.

7 Some insight into the reasons why it was thought necessary to develop and adopt the new model may be gained from Adrian Pagan's report for the Bank of England (Pagan, 2003); see also the Bank of England's reply (Bank of England, 2003).

8 http://www.bankofengland.co.uk/publications/other/beqm/modcobook.htm 


\subsection{Importance of expectations}

The Phillips curves above are forward looking, with inflation expectations playing a key role. At the same time inflation expectations are a yardstick for the credibility of monetary policy. The Bank of England makes use of inflation expectations in its older model which put weight on past inflation and the inflation target:

$$
\pi_{t}^{e}=\mu \pi_{t-1}+(1-\mu) \pi_{t}^{*}
$$

where $\pi_{t}^{*}$ is the inflation target. In the Bank of England's model this equation is simulated with the Phillips curve to check the effects of changes on the bank's credibility. If no credibility is present, (i.e. $\mu=1$ ) it would indicate that the equilibrium inflation level is determined solely by cumulated output gap and supply-side terms but not directly by monetary policy itself. If perfect credibility is present $(\mu=0)$, then the speed of convergence to the target inflation rate will depend on the stickiness of wages and prices. Thus, the Bank of England holds that changes in credibility impact both the transmission lag between output and inflation and the variability of inflation.

In this respect an experiment is presented which tests different forms of credibility (Bank of England, 1999). The Phillips process and the equation for inflation expectations were used in a simulation of two stylised economic cycles which lasted 6 years in one case and 10 years in the other. The simulation illustrates the impact of credibility on inflation. The results indicate that strong credibility can significantly increase the speed of convergence to the inflation target and reduce the variability of inflation.

Table 2.1 Economic cycles and inflation.

\begin{tabular}{lcc}
\hline & $\begin{array}{c}\text { Low credibility } \\
(\mu=0.8)\end{array}$ & $\begin{array}{c}\text { High credibility } \\
(\mu=0.2)\end{array}$ \\
\hline $\begin{array}{l}\text { Lag before output has maximum } \\
\text { effect on inflation }\end{array}$ & $5.7-9.0$ quarters & $\begin{array}{c}4.2-5.6 \text { quarters } \\
1.4 \%-2.3 \%\end{array}$ \\
\hline
\end{tabular}

Source: Bank of England (1999).

The impact of output shocks is felt sooner with increased credibility and the rate of inflation is reduced. The functional form of inflation expectations and credibility are important determinants of monetary policy's success.

The Bank of England published an update of its model in 2000 which placed still greater emphasis on the presentation of price expectations. Two kinds of possibilities are presented therein. At issue, on the one hand, is a model that is the moving average of inflation in previous periods. The data on which the estimate is based go 10 years back in time. On the other hand, a model similar to but somewhat more complex than the one noted above is considered.

$$
I N F E_{t}=1.1+1.2 I N F_{t-1}-0.6 I N F_{t-2}
$$


Here INFE denotes annual inflation expectations and INF is annual inflation (i.e. over four quarters).

The other version contains both forward and retroactive parts where the target inflation rate and thus the credibility of monetary policy have weight:

$$
I N F E_{t}=Z_{1} I N F_{t-1}+Z_{2} I N F_{t}+Z_{3} I N F_{t+4}+\left(1-Z_{1}-Z_{2}-Z_{3}\right) Z P S T A
$$

Notation is as before with the addition that ZPSTA denotes the target inflation rate of the authorities

The model is not estimated but instead the coefficients are given values $\left(Z_{1}, Z_{2}\right.$ and $\left.Z_{3}\right)$. The coefficient values embody different assumptions about expectations. Pure adaptive expectations may be represented by $Z_{1}=1, Z_{2}=Z_{3}=0$. The lower $Z_{1}, Z_{2}$ and $Z_{3}$ are, the greater the weight of the inflation target and the credibility of monetary policy.

The above discussion indicates the origins of the inflation expectations equations in the CBI's model. At the same time the Bank of England's analysis underscores the importance of the way expectations are presented. The Bank of England has sought to examine different forms of price expectations with equations estimated statistically as well as equations that do not involve statistics. It is noteworthy how the Bank of England subjects the speed of convergence to sensitivity analysis based on different credibility assumptions. It should be noted, however, that the Bank of England's new model is no longer based on inflation expectations made explicit in an equation.

\section{Statistical foundations of the QMM inflation equation}

Guðmundsson (2008) discusses the QMM inflation equation (Phillips curve) and tests it against an inflation equation of the kind used at the CBI before the model was developed. Equations for inflation and inflation expectations are presented with the following expectations-augmented Phillips process in QMM:

$$
\begin{aligned}
\Delta c p i_{t}= & 0.741 I N F E_{t} / 4+0.059 \Delta p m_{t}+0.080 \Delta p m_{t-1} \\
& +(1-0.0741-0.059-0.080) \Delta u l c t_{t-1}+0.072 G A P A V_{t-1} \\
I N F E_{t}= & 0.3 I N F E_{t-1}+0.3 I N F_{t-1}+0.4 I T_{t}
\end{aligned}
$$

Here $\Delta c p i$ denotes the logarithmic change in the consumption price index between quarters, ${ }^{9}$ INFE stands for inflation expectations on an annual basis, measured by the difference between the interest rates of non-indexed and indexed treasury bills less a risk premium amounting to 0.5 per cent, $\Delta p m$ is the logarithmic change in import prices, $\Delta u l c t$ is the logarithmic change in wage costs per unit output, GAPAV is output gap (deviation of output from trend), and IT is the annual target inflation rate (2.5\%). The old inflation equation, based on quarterly data from 1994 to 2004 has the form

9 Recall that logarithmic differences are very close to percentage changes for relatively small changes. 


$$
\begin{aligned}
& \Delta c p i_{t}=0.0079-0.042\left(c p i_{t-1}-u l c t_{t-1}\right)-0.035\left(c p i_{t-1}-p m_{t-1}\right) \\
& +0.12 \Delta u l c t_{t-1}+0.10 \Delta p m_{t}+0.08 \Delta p m_{t-1} \text {. } \\
& R^{2}=0.535 ; \quad s=0.00467 ; \quad t \text {-values in parentheses. }
\end{aligned}
$$

Guðmundsson shows that it is difficult statistically to choose between equation (6) and equation (8), i.e. the equations have similar statistical characteristics. ${ }^{10} \mathrm{He}$ also shows that if a constant is added to equation (6), which may be interpreted as the possibility that actual inflation expectations are constant rather than proportional to measured expectations, then the estimated parameter for inflation expectations is reduced from 0.74 to 0.26 and becomes in fact insignificantly different from zero. In Guðmundsson's words, the data are then "useless for distinguishing between these measures of inflation expectations".

In the CBI's model the equation for inflation expectations is not estimated through statistical methods but rather the parameters are presented as follows:

$$
I N F E_{t}=\omega_{p e}\left(I N F E_{t-1}+\eta_{p e}\left(I N F_{t-1}-I N F E_{t-1}\right)\right)+\left(1-\omega_{p e}\right) I T_{t} .
$$

Inserting these parameter values yields equation (7).

This equation, which describes expectations as a weighted average of the inflation target (IT) and adaptive expectations, is presented without further justification and mirrors in fact the opinion of the QMM authors on how inflation expectations will develop. In Guðmundsson (2008) it is shown that if the equation's parameters are estimated in light of available data since the CBI adopted an inflation target in 2001 until the reduction in the value-added tax rate in 2007, a completely different conclusion is arrived at, i.e.

$$
\begin{aligned}
& I N F E_{t}=\underset{(6.5)}{0.97 I N F E_{t-1}}-0.05 I N F_{t-1}+0.08 \cdot 0.025 \\
& R^{2}=0.69 \quad s=0.0056 .
\end{aligned}
$$

( $t$-values in parentheses and the sum of parameters constrained to equal one) where the variable $I T$ has been set equal to the actual inflation target, $I T_{t} \equiv 2.5 \%$. Here the estimated parameter for lagged expectations comes close to being equal to one; the parameters for lagged inflation and the target inflation rate, which is in fact the constant in the equation, are insignificantly different from zero. This means in effect that inflation expectations - or rather the inflation premium on bonds - are much more similar to a socalled random walk than to the relatively speedy adaptation process towards the inflation target described by equation (7). Equation (10) implies that the expectations lead an almost independent life - move up and down in a rather slow and random

10 According to Guðmundsson (2008) equation (6) explains some features of the data which equation (8) cannot explain, and vice versa. This is the conclusion of a statistical test where a forecast value from equation (6) is added as an explanatory value in equation (8) and vice versa. 
manner. If convergence towards a long-term value (inflation target) occurs then it is only over a very long period of time.

It should be noted that a better model for inflation expectations than the one discussed here may exist. However, the focus here is first and foremost on the CBI's actual model and therefore we limit our attention to the same functional form for expectations as in the QMM model. The estimated equation (10) then serves the purpose of summarising the statistical properties of the expectations proxy, i.e. the interest rate differential on non-indexed and indexed bonds.

Two principal conclusions may be drawn from Guðmundur Guðmundsson's statistical conclusions:

1. The statistical case for including an inflation premium on bonds, the yardstick of inflation expectations in QMM, in a forecasting equation for inflation is weak. An equation including constant expectations performs statistically almost as well as does equation (6), i.e. the forecasting equation from QMM.

2. Equation (7), which is used to forecast inflation expectations (inflation premium) in QMM, is not estimated statistically and reflects only the views of QMM's authors on development of inflation expectations. A statistical evaluation of an equation of the same functional form yields different parameter values reflecting properties close to a random walk.

Although there is only weak statistical support for inflation expectations in a forecasting equation for inflation, equation (7), that equation is more in accordance with economic theory than equation (10). ${ }^{11}$ That is presumably the reason why the authors of QMM have chosen to use this equation. At the same time it should be noted that the proxy variable for inflation expectations in QMM - the yield spread between non-indexed and indexed bonds - may, for several reasons, not reflect the theoretical construct that the Phillips-curve relies on particularly well. For example the public's inflation expectations are considerably different from this measure (see e.g. Figure I.8 in the CBI's Economic Indicators, May 2008). This may explain the non-significance of the inflation premium in the inflation equation when constant expectations are allowed for.

\section{Dynamic attributes of QMM}

It is readily apparent when equations (6) and (7), QMM's inflation equation and expectations equation, are examined that the large weight of expectations in the inflation equation and the inflation target in the expectations equation entail a strong propensity for inflation to trend towards the target. Thus it is shown in the QMM handbook (table

11 Nevertheless an economic rationale may be found for equation (9) in that it can be viewed as a reduced form equation with expectations where inflation expectations are determined by lagged changes in wages and import prices as well as deviations from long-term relationships. 
7.1(b) p. 54) that, when solved simultaneously, the long-term solution of these two equations is

$$
\Delta c p i=0.621 I T / 4+0.203 \Delta p m+0.176 \Delta u l c t .
$$

It is also shown that it takes only about eight quarters for this solution to emerge. If import prices and wages per unit output increase in line with the inflation target then these two equations indicate that the inflation target will be attained in about two years almost independent of the initial level of inflation or expectations. This, of course, is already a very strong indication that the pattern shown in Figure 1.1 is systemic, i.e. that convergence to the inflation target in approximately two years is built into the model. Yet this is something that cannot be asserted without testing the model's timedependent attributes as a whole through simulation. Thus changes in wages and the exchange rate could have effects such that this rapid convergence to the inflation target would be disrupted. This study does not go so far as to simulate the whole model. Instead, the approach chosen is to add equations for import prices (exchange rate) and wages. This makes it likely that those factors are taken into account which have the greatest influence on the price level, exchange rate and wages over a relatively short period of time, i.e. a few quarters. Demand effects, which affect the long-run price level, are viewed as exogenous. The effects of this simplification are discussed in more detail below.

\subsection{Simplified version of the CBI's QMM model}

The CBI's macroeconomic model includes approximately 150 economic quantities and is too large to be suitable for the study addressed in the present paper. Therefore it was decided to prepare a simplified version of the model covering the factors being addressed here. This "partial model" includes (naturally) the QMM equations which determine inflation and inflation expectations. Also included are equations for the exchange rate and wages which are important causal factors for prices in the short run. Also included was the QMM policy interest rate equation, since the policy interest rate is a key determinant of exchange rate developments. Therefore, the partial model includes the following equations from the CBI's QMM model (the numbers of equations and page numbers are from the CBI's QMM handbook):

1. Consumer price index (equation 7.1, p. 52)

2. Inflation expectations (equation 7.17, p. 66)

3. Exchange rate (equation 4.8, p. which also determines changes in import prices (equation 7.2, p. 54)

4. Wages per unit output (equation 6.2, p. 45)

5. Interest rates (equation 4.1, p. 18)

Thus the partial model's endogenous variables are as follows:

CPI Consumer price index. 
INFE Inflation expectations on an annual basis, measured by the difference between interest on non-indexed and indexed treasury bills less a risk premium of 0.5 per cent.

EER Exchange rate index for the Icelandic króna.

ULCT Wage cost adjusted for productivity changes (trend).

$R S \quad$ CBI policy interest rate (annual yield)

Equations for these variables are presented in the following manner in QMM: ${ }^{12}$

$$
\begin{aligned}
\Delta c p i_{t}= & 0.741 I N F E_{t} / 4+0.059 \Delta p m_{t}+0.080 \Delta p m_{t-1} \\
& +(1-0.0741-0.059-0.080) \Delta u l c t_{t-1}+0.072 G A P A V_{t-1} \\
I N F E_{t}= & 0.3 I N F E_{t-1}+0.3 I N F_{t-1}+0.4 I T_{t} \\
\text { eer }_{t}= & 0.75\left(e e r_{t-1}-r d_{t}\right)+0.25\left(0.021+e e r_{t-1}+0.386 r e x_{t-4}\right) \\
\Delta u l c t_{t}= & \Delta p g d p_{t}-0.842 \Delta\left(p g d p_{t}-c p i_{t}\right)-1.247\left(U R_{t}-N A I R U_{t}\right) \\
& +0.353\left(U R_{t-4}-N A I R U_{t-4}\right)+0.118 r e x_{t-1}-0.640(u l c t-p g d p)_{t-1} \\
& +(\text { constant, dummies and trend }) \\
R S_{t}= & 0.5 R S_{t-1}+0.5\left[\left(R R N_{t}+I T_{t}\right)+1.5\left(I N F_{t}-I T_{t}\right)+0.5 G A P A V_{t}\right]
\end{aligned}
$$

Here lower case letters denote that logarithm has been taken of the variables concerned (i.e. $\left.x_{t}=\log \left(X_{t}\right)\right)$ and $\Delta$ that the difference between quarters is taken (i.e. $\left.\Delta x_{t}=x_{t}-x_{t-1}\right){ }^{14}$

Equation (12) is an inflation equation which predicts changes in consumer prices between quarters. The variables in the equation are inflation expectations (weight 0.74 ), changes in import prices $(\Delta p m$, combined weight 0.14$)$, and changes in productivityadjusted wages (weight 0.12). In addition, excess demand in the economy increases inflation: A positive output gap (GAPAV) will tend to increase inflation and a negative output gap will do the reverse. In equation (13) inflation expectations - the single most important causal factor in inflation - are predicted with lagged inflation expectations (weight 0.3), lagged inflation (weight 0.3 ) and the CBI's inflation target (IT, weight 0.4). As will be discussed in more detail later in this report, this equation is decisive for determining whether and how inflation trends towards the inflation target.

12 The equations are presented here after parameter values have been specified and substitutions made for some variables. In some cases, therefore, they look slightly different from the QMM equations, but are equivalent based on information in the QMM manual.

13 In this equation the substitution is made that the expected exchange rate is equal to the lagged exchange rate, i.e. $E\left[e e r_{t+1}\right]=e e r_{t-1}$. According to equation (4.9) in the QMM handbook this is then the same equation as the one used in the CBI's forecasts.

14 The exception for the meaning of lower case variables is $r d$ which is defined as $r d=\log ((1+R S / 4) /(1+R F / 4)) \approx(R S-R F) / 4$, where $R F$ is the sum of foreign short-term interest rates and a risk premium for the Icelandic króna. 
In equation (14) the exchange rate is predicted with a weighted average of two common explanatory factors for the exchange rate. Greatest weight, or 0.75 , is given to the assumption that uncovered interest differential with respect to abroad is reflected precisely in exchange rate changes. ${ }^{15}$ An equation which is based on long-run purchasing-power-parity has a weight of 0.25 .

Equation (15) predicts productivity-adjusted wage changes beyond GDP price level changes $\left(\Delta p g d p_{t}\right)$ with variables which reflect demand pressure in the labour market (difference between unemployment and natural unemployment $U R-N A I R U$ ) in addition to the real exchange rate ( $r e x)$, the difference between changes in the GDP price level and consumer prices, and the ratio of wages and the GDP price level. Finally there is equation (16), the so-called Taylor-rule with an interest rate equation, which describes how the CBI determines the policy interest rate. Lagged interest rates have a weight of 0.5 , but the principal causal factors are, on the one hand, inflation beyond the inflation target, which has a weight of 0.75 and, on the other hand, an output gap with a parameter of 0.25 . With this equation the CBI predicts its own conduct, i.e. how it changes the policy interest rate in accordance with developments in inflation and demand. If the economy is in equilibrium, i.e. inflation is equal to the inflation target and there is no output gap, then the equation predicts that the policy interest rate will tend to the sum RRN and IT (now 5.5\%). The CBI's handbook provides more detailed explanations of the economic and empirical foundations of these equations as well as their dynamic characteristics. Variables on the right hand side of the above equations which are derived directly from the partial model's endogenous variables are the following:

INF Percentage change in the consumer price index over one year.

$P M \quad$ Import price index, changes with exchange rate. ${ }^{16}$

$R D$ Interest rate differential between Iceland and abroad (on quarterly basis), changes with the CBI's policy interest rate.

REX Real exchange rate measured by consumer price index.

Exogenous variables are the following:

GAPAV Average output gap (percentage difference between gross domestic product and estimated output capacity) during past four quarters.

IT CBI's inflation target, now $2.5 \%$.

$R R N \quad$ "Neutral" real interest rates, set at 3\% in QMM data base.

15 I.e. if interest rates in Iceland are 1\% higher than foreign interest rates on a quarterly basis, then the exchange rate of the króna will depreciate by $1 \%$. The QMM does in fact assume a certain fixed risk premium for the Icelandic króna.

16 In QMM the exchange rate effects appear for the most part in the same period (cf. equation 7.2 on p. 54 of the QMM manual), but part of them is lagged. 
As noted before, it was necessary to simplify some of the above equations in order to present an integral partial model with appropriate links between variables. It must be borne in mind that under consideration here first and foremost are comparisons of specified scenarios given unchanged exogenous circumstances. Since those variables enter linearly into the equations their non-inclusion in the partial model does not influence the results.

Equations simplified were those for the exchange rate, equation (14), and wages, equation (15). ${ }^{17}$ Equation (14) was simplified by assuming that foreign interest rates and a risk premium on the króna are fixed quantities. It was also assumed that import prices move in step with foreign consumer prices. Neither assumption influences the conclusions presented in this report since being considered, as noted before, are comparisons of specified scenarios given unchanged exogenous circumstances. With these simplifications having been made, the following equation was derived:

$$
\begin{aligned}
\Delta e e r_{t} & =0.75\left(\Delta e e r_{t-1}-\Delta r d_{t}\right)+0.25\left(\Delta e e r_{t-1}+0.386 \Delta \text { rex }_{t-4}\right) \\
& =\Delta e e r_{t-1}-0.75 \log \left(\frac{1+R S_{t} / 4}{1+R S_{t-1} / 4}\right)+0.25 \cdot 0.386 \cdot\left(\Delta c p i_{t-4}-\Delta p m_{t-4}\right)
\end{aligned}
$$

Equation (15) was simplified by assuming that a) the GDP price level will move in line with consumer prices; b) that the import price level measured in foreign currency will move in line with foreign consumer prices; c) that unemployment and NAIRU are exogenous quantities so that omitting them will not invalidate comparisons between scenarios. At the same time a constant equal to 0.025 was put in place of constants, dummy variables and trend. Following these simplifications the equation takes the following form:

$$
\Delta u l c t_{t}=0.025+\Delta c p i_{t}+0.118\left(\Delta c p i_{t-1}-\Delta p m_{t-1}\right)-0.64\left(u l c t_{t-1}-c p i_{t-1}\right)
$$

Therefore the partial model comprises the following equations:

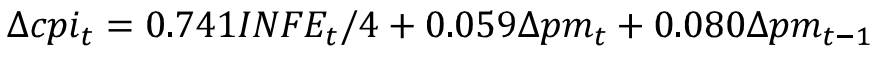

$$
\begin{aligned}
& +(1-0.0741-0.059-0.080) \Delta u l c t_{t-1}+0.072 G A P A V_{t-1} \\
& I N F E_{t}=0.3 I N F E_{t-1}+0.3 I N F_{t-1}+0.4 I T_{t} \\
& \Delta e e r_{t}=\Delta e e r_{t-1}-0.75 \log \left(\frac{1+R S_{t} / 4}{1+R S_{t-1} / 4}\right)+0.25 \cdot 0.386 \cdot\left(\Delta c p i_{t-4}-\Delta p m_{t-4}\right) \\
& \Delta u l c t_{t}=0.025+\Delta c p i_{t}+0.118\left(\Delta c p i_{t-1}-\Delta p m_{t-1}\right)-0.64\left(u l c t_{t-1}-c p i_{t-1}\right) \\
& R S_{t}=0.5 R S_{t-1}+0.5\left[\left(R R N_{t}+I T_{t}\right)+1.5\left(I N F_{t}-I T_{t}\right)+0.5 G A P A V_{t}\right]
\end{aligned}
$$

In addition, the model includes the following "technical relationships":

$$
\begin{aligned}
& \Delta p m_{t}=\log (1.025) / 4+\Delta e e r_{t} \\
& I N F_{t}=C P I_{t} / C P I_{t-4}-1
\end{aligned}
$$

17 One may also say that the simple relationship between the exchange rate and import prices used in the partial model is a simplification of the QMM equation for import prices. 
In the former equation import prices are projected in line with exchange rate changes and foreign inflation is assumed to be $2.5 \%$ on an annual basis; in the latter equation the annual rate of inflation is projected on the basis of the consumer price index.

\subsection{Scenarios}

Here dynamic characteristics of the partial-model interaction between inflation expectations and inflation are examined by inserting a shock into inflation expectations; the shock is temporary and lasts one quarter. Before the shock is inserted the model is simulated for approximately 40 quarters, attaining long-term equilibrium where inflation is equal to the inflation target and other variables are stable. We are not interested in this underlying example in and of itself but rather in the response to the shock. Therefore the results are presented as a deviation from a base simulation free of shock.

As noted in Section 2, the parameter for the inflation target in the expectation equation is a measure of the CBI's credibility: the higher this parameter, the faster inflation may be expected to approach the target. To verify this and examine the results of reducing credibility, we simulate the model in two additional versions with differing expectation equations. In the first one (scenarios 2 and 3) the weight of the inflation target (parameter $\omega_{p e}$ ) in the expectations equation (9) is reduced from 0.4 to 0.2 . In the second version use is made of the expectations equation (10) from Guðmundsson (2008) (Scenarios 4 and 5). Thus the following scenarios are simulated:

- $\quad$ Scenario 0 - base run: Expectations equation from QMM. No shock.

- Scenario 1: As Scenario 0 with the addition of a shock involving 1\%-point increase in inflation expectations which lasts one quarter.

- Scenario 2: Same as Scenario 0, but weights in the QMM expectations equation changed with less weight on inflation target (20\% instead of $40 \%$ ).

- Scenario 3: Same as Scenario 2 with the addition of a shock involving 1\%-point increase in inflation expectations which lasts one quarter.

- $\quad$ Scenario 4: Same as Scenario 0 except the inflation expectations equation weighted as in Guðmundur Guðmundsson (2008), i.e. as in equation (10).

- Scenario 5. Same as Scenario 4 with the addition of a shock involving $1 \%$-point increase in inflation expectations which lasts one quarter.

The following figures show deviations in Scenarios (1 from 0), (3 from 2), (5 from 4). 
Figure 4.1 Inflation expectations (annual basis).

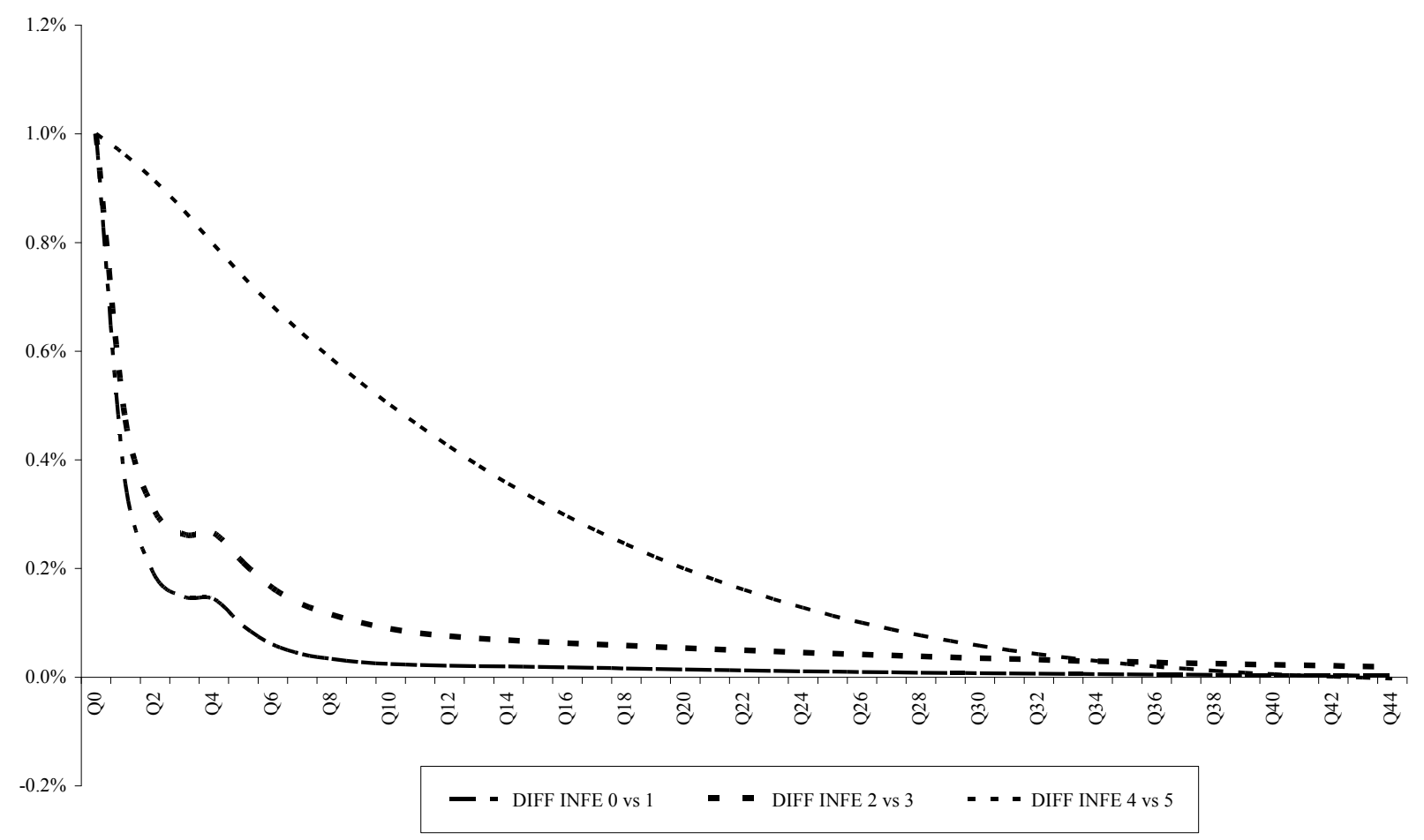

In Figure 4.1, which shows simulated inflation expectations, the inflation expectations shock is felt with full force in the first quarter. While the shock itself disappears after one quarter, its effects last longer. With a credible inflation target as assumed in QMM $\left(\omega_{p e}=0.4\right)$ these effects peter out rather quickly and after 5 quarters only one-tenth of the shock remains. With less credibility $\left(\omega_{p e}=0.2\right)$ it takes approximately twice that time for the effects to diminish to this extent. With an estimated expectations equation (equation (10)) it takes five times longer, or approximately 26 quarters, for the system to attain equilibrium in the above-mentioned sense. ${ }^{18}$

18 The reason for the "step" which appears in the paths after four quarters is that annual inflation - a right-hand-side variable in the expectations equation - attains its maximum rate at that point. 
Figure 4.2 Quarterly inflation.

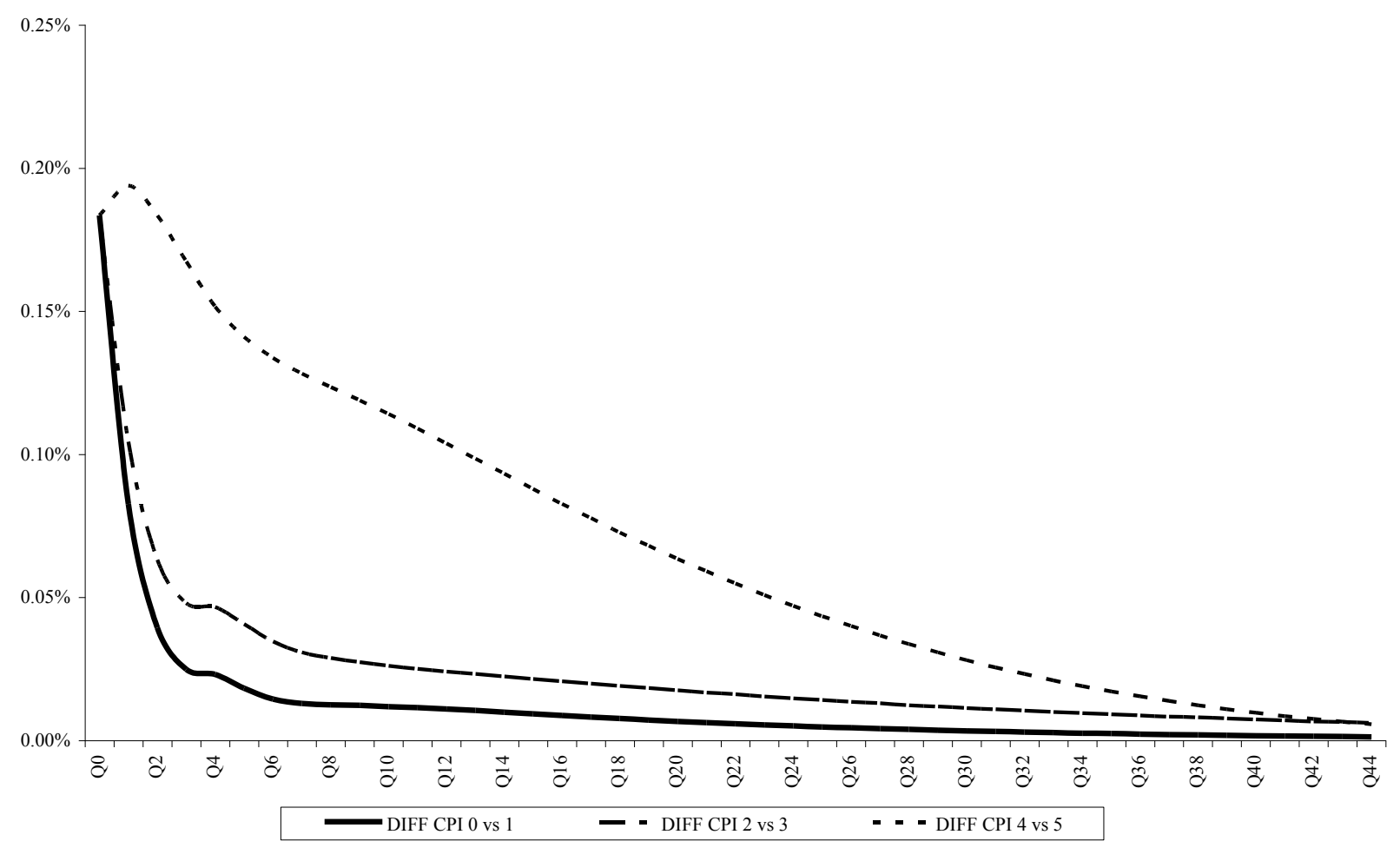

The effects of an expectations shock on quarterly inflation are shown in Figure 4.2. ${ }^{19}$ The pattern here is similar to that in the case of inflation expectations, i.e. given a credible inflation target $90 \%$ of the shock's effects have petered out after 5 quarters. It is noteworthy, however, that with less credibility $\left(\omega_{p e}=0.2\right)$ it now takes more time, or 17 quarters, for the effects to vanish and the same holds in the case where equation (10) is used to describe expectations, where it takes 27 quarters. A similar story is depicted in Figure 4.3 which shows quarterly wage changes.

19 Note that numbers can be annualised by multiplying by 4 . Therefore, the effects of inflation expectations in the quarter when the shock is inserted are an increase of $0.7 \%$ on an annual basis according to equation (1). 
Figure 4.3 Quarterly wage changes.

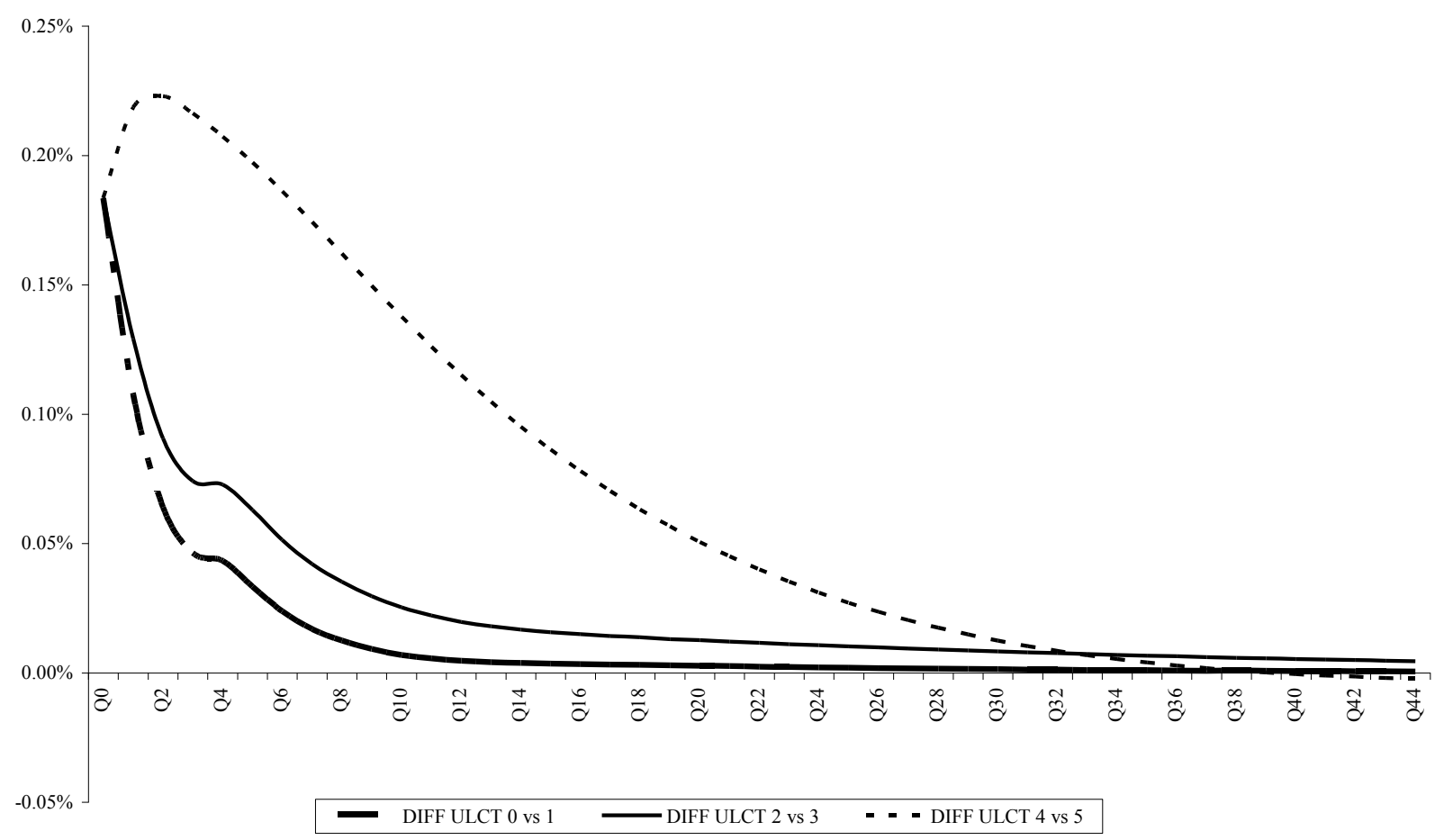

Figure 4.4 Annual inflation.

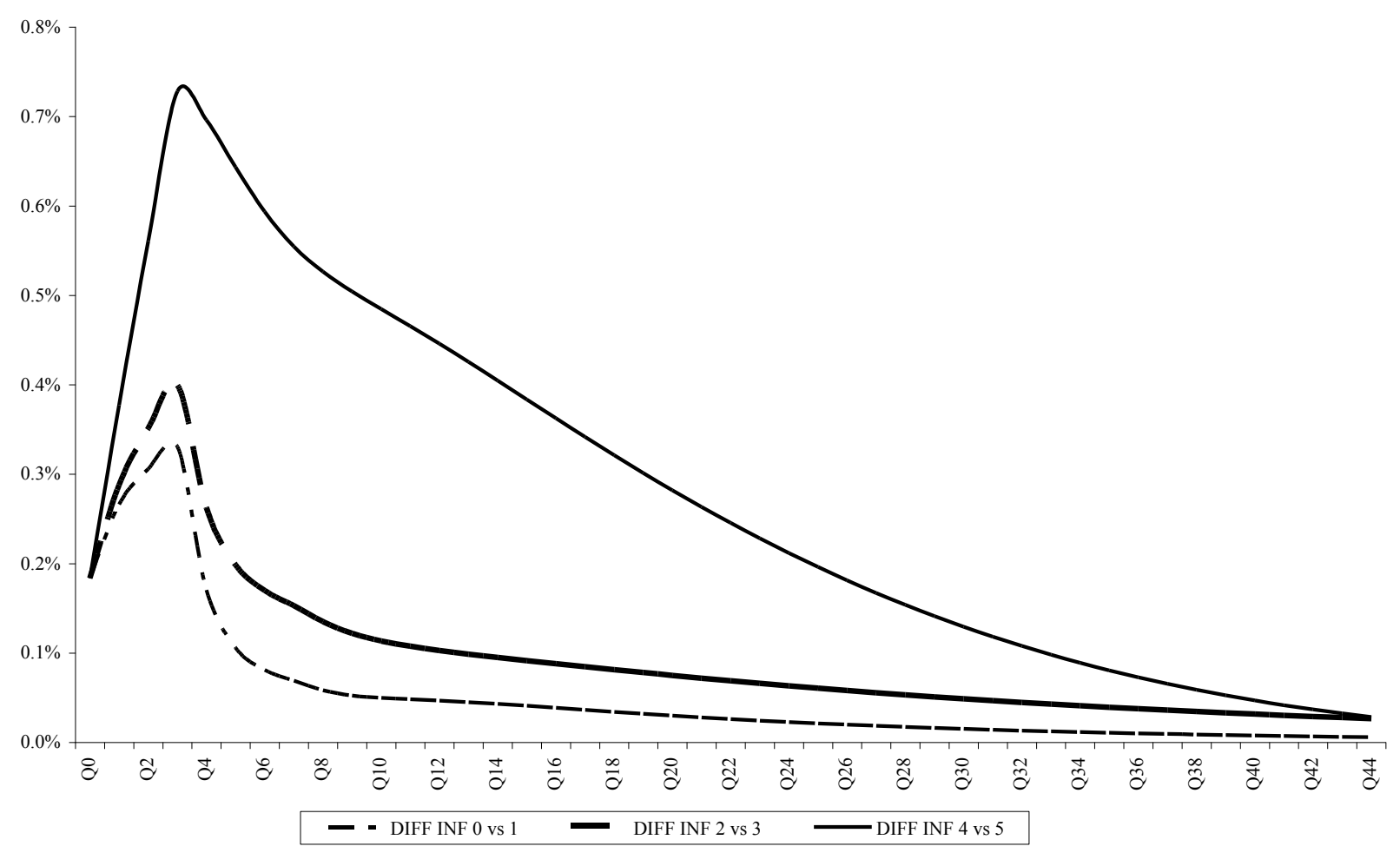


Figure 4.4 shows the effects of an expectations shock on annual inflation. It takes one year for the shock to be felt fully, but then its effects peter out in a pattern similar to that in the case of quarterly inflation. It may be noted here that due to cumulative effects the total effects on inflation are considerably greater in the case where the estimated expectations equation is used than when equation (7) or a comparable equation with less credibility is used; the inflation peak is more than twice as high when the estimated expectations equation is used instead of the QMM equation. Figure 4.5 shows how the policy interest rate responds to the expectations shock. It may be noted that the effects of a reduced credibility parameter are rather to extend the period during which interest rates are higher than to raise interest rates above their level when equation (7) is used. However, the interest rate path is different when an estimated expectations equation is used, in which case interest rates are more than twice as high as compared to the case of equation (7).

Figure 4.5 Policy interest rate.

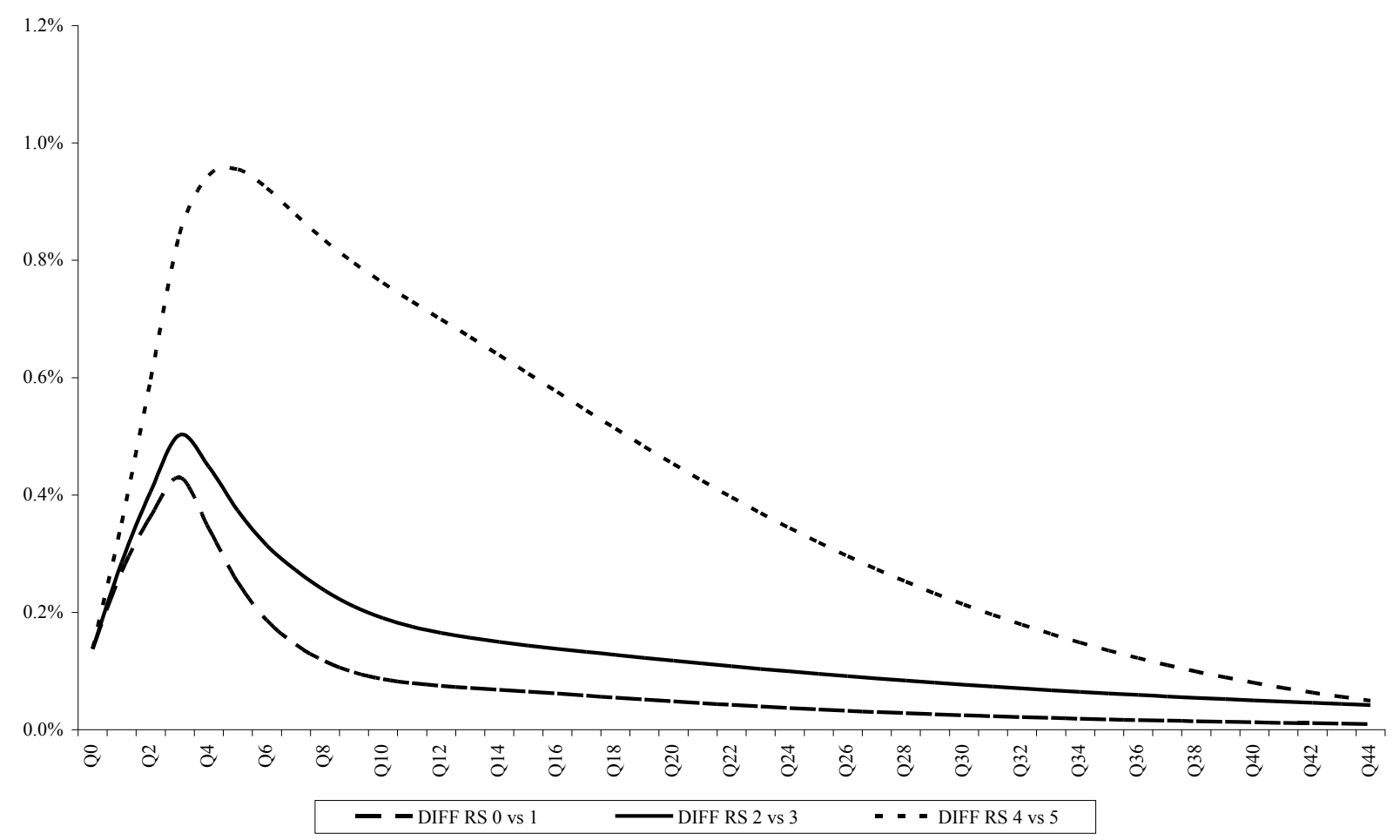

Figure 4.6 shows how the exchange rate responds to the expectations shock. At first the exchange rate appreciates because interest rates increase, but then it depreciates reflecting lower interest rates and the purchasing power parity assumption. 
Figure 4.6 The exchange rate.

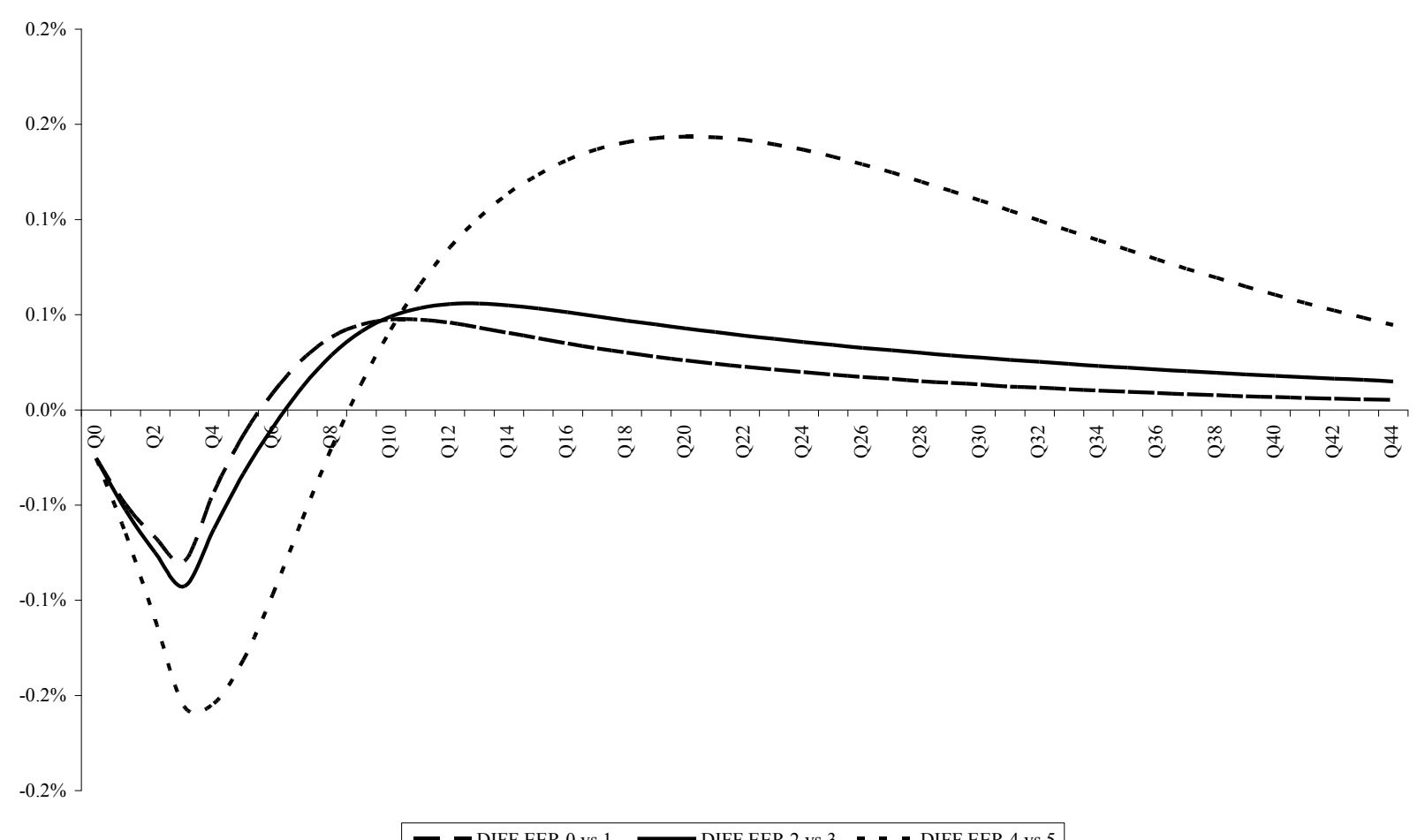

These simulation results may be summarised as follows:

1. The time it takes to attain the inflation target is very sensitive to the credibility parameter in the expectations equation. The lower credibility is, the longer it takes to attain the target.

2. With the estimated expectations equation (10), whose functional form is the same as that of the QMM equation, the credibility parameter becomes very low and convergence takes correspondingly longer. Results are qualitatively different and fluctuations considerably greater.

\section{Effects of simplifying assumptions}

In this study we have relied on a highly simplified version of QMM. In principle two kinds of simplification are made. On the one hand, specified variables are assumed to follow related variables, e.g. the GDP price level (used in the wage equation) follows consumer prices. On the other hand, demand effects of interest rates are neglected. In turn, this means that real variables which affect the price level (output gap and unemployment) are treated as exogenous.

The effects of these simplifying assumptions are probably relatively limited in the short run (a few quarters). The reason is that it takes long for interest rates to affect demand, 
and then it takes time for demand effects to impact the price level. ${ }^{20}$ Therefore, any "error" - i.e. deviation from the corresponding paths in the full QMM model - in the scenarios developed in this study is likely to occur primarily in their later stages when the effects being studied have for the most part dwindled. It may be expected, however, that if output gap and unemployment were endogenous quantities in our model (as they are in QMM), then that would increase the downward pressure of the policy interest rate on prices and entail more rapid price level convergence towards target. This would cause convergence to be somewhat more rapid than is the case with the results we obtain here. These effects would have a similar qualitative impact on all the paths, leaving the comparative results unchanged. Quantitatively the effect would be strongest in scenarios with the estimated expectations equation which would bring the results in that case closer to results with the QMM equation. However, we would not expect the main qualitative results regarding the comparison between path characteristics stated above to change.

It would seem, therefore, that the effects of these departures from the CBI model are limited with respect to the factors under study, and the report's substantive conclusions are unlikely to have been significantly different if the model as a whole had been used in the study.

\section{Discussion and conclusion}

This study has examined dynamic characteristics of inflation in the CBI's macroeconomic model by simplifying the model and relying on data published by the bank.

The rapid convergence towards the inflation target reflected in the CBI's inflation forecasts in the recent past appears to be a built-in attribute of the bank's macroeconomic model. ${ }^{21}$ The arguments presented here suggest this reflects the model's assumption that the bank's monetary policy is credible. In this context, credibility means it is generally expected that the CBI can attain its inflation target within an acceptable period of time. That assumption is reflected in the inflation target's weight in the equation for inflation expectations. In turn, inflation expectations exert a considerable influence on the bank's inflation forecasts. The same is true of the Bank of England's model (1999-2004 version), but the documentation for that model addresses the effects of expectations and examines different forms thereof. There is relatively little analysis of the CBI's inflation expectations equation in the model's handbook and it is not estimated statistically. ${ }^{22}$ The bank's assumptions on inflation expectations and their effects on

20 Recall that account is taken of the effects of interest rates on the exchange rate which is the fastest and most effective impact of monetary policy on prices.

21 It is important to note that the model includes a Taylor-rule which simulates the responses of the Central Bank to inflation. The bank has followed such a rule quite closely since 2003.

22 This should not be taken as implying that inflation expectations are not studied at the Central Bank; see Magnús F. Guðmundsson (2008) and Pórarinn Pétursson (2008) for recent work by 
inflation probably explain why the $\mathrm{CBI}$ forecasts tend to the inflation target in approximately two years.

As already noted, the CBI has not estimated its inflation expectations equation by econometric methods. In addition Guðmundsson (2008) shows that the measure used as a proxy for inflation expectations - viz. the interest rate differential on non-indexed bonds over indexed - has a weak statistical basis in the inflation equation. Guðmundsson also estimates an equation for expectations based on the same functional form as used by the CBI. Naturally, the estimated equation fits the observational data better. Moreover, the coefficients are quite different; in particular the inflation target's weight in the estimated equation is low. ${ }^{23}$ If the CBI's equation is replaced by its estimated counterpart in simulations, the result is considerably slower convergence towards the inflation target and more variation in inflation and other simulated variables including the policy rate and exchange rate. It should be noted that this study is purely positive in that it is limited to a description of the forecasting results of the CBI and a study of the underlying reasons for the patterns observed. We do not propose an alternative expectations mechanism and our use of the estimated equation (10) should not be taken as a recommendation to use that particular equation for predicting inflation expectations.

As noted by Pagan (2003) there is always a trade-off in macroeconomic modelling between theoretical coherence - the way the model-builder considers the economy to function - and empirical coherence - the ability of the model to replicate historical data. This observation would seem particularly relevant here. Theoretical coherence in the present case is provided by the result that the inflations expectations equation (9) in QMM may be derived based on the assumption that agents, uncertain about the central bank's commitment to bringing down inflation, gradually learn about the actual level of commitment by observing the bank's actions. ${ }^{24}$ It could be hypothesised that CBI modellers use this equation in their forecasting in order to 'bootstrap' the bank's credibility and transform historically high and volatile inflation expectations to a new era of low and stable expectations. ${ }^{25}$ This has not worked so far, which may be interpreted either as an indication that the Central Bank has not been strict enough in its actions or not transparent enough about its future policy, or as a reflection of general

CBI staff involving inflation expectations. In particular Guðmundsson shows how volatile and unpredictable expectations, as implied by the term structure of interest rates, have been of late.

23 Our use of this equation does not imply that we hold the functional form itself to be correct; further study is required to resolve that question.

24 We thank Pórarinn Pétursson for pointing this out.

25 This may also be seen as following the strategy of Kapetanios, Pagan and Scott (2007) where theory takes precedence over data-determined relationships in deciding model relations. 
doubt that inflation targeting is likely to succeed. The outcome is therefore lacking in empirical coherence in Pagan's terminology. ${ }^{26}$

Indeed, recent research shows that inflation targeting in Iceland is bound to be an extremely difficult task unless some fundamentals - e.g. volatile demand and exchange rate - change. In particular, Hunt (2006) estimates a monetary policy frontier for several countries, including Iceland, and shows that the trade-off between inflation and output volatilities is considerably less favourable in Iceland than in all other countries he studies. Moreover, given optimal monetary policy, inflation will be in the $1-4 \%$ range aimed at in the current inflation targeting regime only about $60 \%$ of the time. Pétursson (2008) studies inflation volatility in a large sample of countries, including Iceland, and finds that due to several underlying factors (e.g. exchange rate volatility and high passthrough to domestic prices) very small open economies such as Iceland are likely to exhibit high inflation volatility, credible and transparent monetary policy notwithstanding.

Since gaining independence, Iceland's Central Bank has used its primary tool - the policy interest rate - to fight inflation. Researchers at the bank have emphasised that credibility is a key factor in a successful monetary policy and have assumed such credibility in their forecasts in order to generate inflation paths that converge to target within an acceptable time horizon. The bank's forecasts of relatively rapid reduction of inflation and interest rates have, however, not been realised. A series of such forecasts would seem likely to undermine the effectiveness of monetary policy. The bank, however, faces a Catch-22 situation: on the one hand its credibility-based forecasts are likely to fail due to volatile fundamentals; on the other hand forecasts that show high and unstable inflation over the medium term are unlikely to bring about confidence in the bank's ability to control inflation.

\section{References}

Bank of England (1999). Economic Models at the Bank of England, Publications Group, London.

Bank of England (2000). Economic Models at the Bank of England: September 2000 Update, Publications Group, London.

Bank of England (2003). Bank's Response to the Pagan Report.

Central Bank of Iceland (2006a). Monetary Bulletin 2006/2.

Central Bank of Iceland (2006b). Monetary Bulletin 2006/3.

Central Bank of Iceland (2007a). Monetary Bulletin 2007/1.

26 The bank is now developing a new model which includes forward-looking expectations and surely aims to be at the frontier of the present trade-off between theoretical and empirical coherence, i.e. to maximize the degree of empirical coherence given a certain degree of theoretical coherence. 
Central Bank of Iceland (2007b). Monetary Bulletin 2007/2.

Central Bank of Iceland (2007c). Monetary Bulletin 2007/3.

Central Bank of Iceland (2008a). Monetary Bulletin 2008/1.

Central Bank of Iceland (2008b). Economic Indicators, May 2008.

Daníelsson, Á., Elíasson, L., Guðmundsson, M. F., Hauksson, B. A., Jónsdóttir, R., Ólafsson, P. T., Pétursson, P. G. (2007). QMM: A Quarterly Macroeconomic Model of the Icelandic Economy, version 1.1, Central Bank of Iceland, available at www.sedlabanki.is.

Guðmundsson, G. (2008). Statistical Analysis of Models of Inflation in Iceland, mimeo., Science Institute, University of Iceland.

Guðmundsson, M. F. (2008). The term structure of interest rates: Extracting information from the Icelandic market, Seminar talk at the Central Bank of Iceland, May 29 2008, see http://www.sedlabanki.is/?PageID=716.

Hunt, B. (2006). Simple Efficient Policy Rules and Inflation Control in Iceland, Central Bank of Iceland Working Paper no. 30.

Kapetanios, G., Pagan, A. \& Scott, A. (2007). Making a match: Combining theory and evidence in policy-oriented macroeconomic modeling, Journal of Econometrics, 136(2), 565-94.

Pagan, A. (2003). Report on modelling and forecasting at the Bank of England, Bank of England Quarterly Bulletin, Spring, 1-29

Pétursson, P. G. (2008). How hard can it be? Inflation control around the world, Seminar talk at the Central Bank of Iceland, February 19, 2008, see slides at http://www.sedlabanki.is/lisalib/getfile.aspx?itemid=5672.

Svensson, L. E. O. (1997). Inflation forecast targeting: implementing and monitoring inflation targeting, European Economic Review, 41(6), 1111-46.

Svensson, L. E. O. (1999), Inflation targeting as a monetary policy rule, Journal of Monetary Economics, 43(3), 607-54.

Woodford, M. (2007), The case for forecast targeting as a monetary policy strategy, Journal of Economic Perspectives, 21(4), 3-24. 
